\title{
FACTORS AFFECTING FOOD SELECTION AND NEW TRENDS IN CONSUMER FOOD BEHAVIOUR ${ }^{*}$
}

\author{
Y. Birol SAYGI ${ }^{1}$, Z. Dilistan SHIPMAN ${ }^{2}$
}

\author{
${ }^{1}$ Prof. Dr., Beykoz University, Head of Gastronomy and Culinary Arts Department, \\ birolsaygi@beykoz.edu.tr, ORCID: 0000-0001-9829-960X \\ ${ }^{2}$ Dr. Istanbul Bilgi University, Head of Gastronomy and Culinary Arts Department, \\ dilistan.shipman@bilgi.edu.tr, ORCID:0000-0001-9381-7295
}

\begin{abstract}
Which products people purchase and consume, how they make their decision is known as the consumers'food choice process. The specs and the features of the products on the package may have an impact on personal food preferences. Other personal factors that affect food choices can be habits or taste preferences. Factors that are even more effective in choosing food are culture and tradition, the way individuals are brought up or the traditional role of food in the family. Our food choices are influenced by a complex group of factors that vary from person to person but can also depend on the culture. It may also depend on our mood or other factors such as our appetite and being in a hurry. The purpose of this article is to identify and discuss the most important trends in consumers' nutritional behaviors that contribute to the development of marketing strategies for food companies. The article shows the theoretical aspects of new trends in consumer food behavior, the marketing strategies of food companies and the interaction between these two aspects.
\end{abstract}

Keywords: Food, Food Selection, Consumers, Consumer Behavior, Nutrition

\section{INTRODUCTION}

Food selection is about what products people buy and eat and how they make decisions. Product characteristics that are visible on the package and affect personal preferences can also affect food selection. Other personal factors that influence food selection can be habits ("I always buy this") or taste preferences ("I like the taste of this"). Even more influential factors in food selection are culture and tradition, the way one is raised or the traditional role of the food in the family. Our food choices are influenced by a complex set of factors that vary from person to person but can also depend on culture. It may also depend on our mood or other factors such as our appetite and being in a hurry.

\footnotetext{
${ }^{1 *}$ Received: 10.01.2021 - Accepted: 15.01 .2021

DOI: 10.17932/EJEAS.2021.024/ejeas_v01i1004
} 
Providing consumers with products that meet their needs and at the same time bring financial profit to their producer is a particularly difficult task for food producers because buyers' preferences arise from the subjective assessment of the sensory quality of foods. The manufacturer must also meet a number of systematic and legal requirements arising from the necessity to ensure the health safety of the manufactured products. Defining the market requirements for a manufacturer is a key marketing task in formulating the company's strategy [14].

The purpose of this article is to identify and discuss the most important trends in the nutritional behavior of consumers that have contributed to the development of marketing strategies for food companies. The article shows the theoretical aspects of new trends in consumers' food behavior, the marketing strategies of food companies and the interaction between these two aspects.

A person eats an average of 70 thousand times in his life, which means approximately 30 tons of food. A large part of this amount of food is consumed for nourishment, that is, to benefit from the nutrients contained in foods. Food is an integral part of people's daily lives. Apart from being a simple daily function, food is important for human health and happiness. Nutrition is the intake of each of the energy and nutrients required for human growth and development, tissue regeneration and functioning in adequate and balanced amounts, and their proper use in the body. Food processing has started in the prehistoric period in parallel with the increase in agriculture and livestock raising; it has become an inevitable phenomenon to protect our food in order to reduce the losses due to spoilage and to survive in times of famine. Food science is a multidisciplinary science. Food has a complex structural character and consumer preferences are at the forefront. Consumer preferences are an intersection formed by the combination of many factors. Examining the factors of this complex structure that affects consumers' choices is crucial for creating a successful product and for a sustainable success $[1,3,5,18,24$, 27, 28, 29].

Physiological Factors: Physiological factors affect the body's need and nutritional desire. It should contain sufficient nutrients for the body to stay healthy and function properly $[2,6,12,13,25,26,31,32,34]$.

Hunger Level: Hunger can be defined as the feeling of emptiness, weakness or pain caused by lack of food. As time passes, it becomes more intense until you think less of food. Hunger is controlled by a small gland in the brain called the hypothalamus. The hypothalamus has important functions in the body and works in coordination with the pituitary gland. It is their duty to control body temperature, regulate appetite, thirst and body fluids, balance sleep and alertness, control growth and various glands and sex hormones in the body.

Appetite: Appetite is the desire for food even when the body is not hungry. Appetite can be triggered by the appearance of the food, the flavor of the prepared food, the word food during speech and thinking. The hypothalamus gland registers these cues through the senses and sends messages that encourage the person to think about food. The salivary glands are stimulated, producing extra fluid, and mouth watering begin. Unlike hunger, if the appetite is not satisfied, it will eventually disappear from the body.

Nutritional Requirements: Consumers make their food choices to stay healthy and feel healthy. Our foods must provide essential nutrients necessary for metabolism. There are five different categories of nutritional requirements: body size / type, age, activity level, gender, and health status. 
Body size / type: Varies in accordance with the nutritional requirements of different human body sizes. Individuals with larger sizes need more nutrients to maintain the functions of their bodies. Likewise, there are people with smaller body sizes that require less protein for the maintenance and repair of their body tissues because their body mass is smaller.

Age: Buyer decisions are affected by extroverted characteristics such as age, stages of family life, lifestyle and personality. There are certain characteristics that can be distinguished from the needs and interests of every age group for example, wellness and diet products for the elderly. Life cycles are also among the factors that affect purchasing decisions. The human body goes through certain growth stages throughout its life. Dramatic changes are seen in body proportions from infancy to adolescence. Arms increase in length and muscle ratio allowing more movement and coordination; their legs are extended to complete half the body height. The growth and development period continue throughout adolescence until the body reaches a more mature form. Since foods carry out special functions within the body, the amount of nutrients an individual needs is regulated by growth processes.

Level of activity: The requirement for a physically active person to consume more energy-giving foods is higher than the person who lives a less active life. A sedentary person requires less nutrients than an active person. If a person consumes a large amount of energy but does not move much, the body stores the excess as adipose tissue.

Gender: The individual's gender also determines the nutritional requirements. Biological activities such as menstruation and childbirth mean that women should take a diet with a higher content of iron and calcium intake. Men have a higher percentage of muscle tissue in their bodies. For this reason, they need to take higher amounts of protein than women. Gender also affects the parts of the body where adipose tissue is stored. Women are more likely to have extra fatty tissue in their upper arms, breasts, waist, hips, and thighs.

Health status: A person's state of health can make the person consume certain types of food less than other foods. For example, if a person has high cholesterol (which can ultimately cause heart disease), he/she should reduce the amount of saturated fats in their diet. Some diseases that may be associated with malnutrition include beriberi, pellagra, rickets, scurvy, osteoporosis, and anemia.

Personal Eating-Drinking Reactions: Our personal perceptions have a huge impact on our food choice. Individuals choose or reject their food based on their reactions to the food's physical appearance, presentation, smell, and texture. We use our senses to measure the quality of food. Judgments based on these reactions are called sensory perceptions. Attractive colors and creative presentations stimulate our appetite. Food preparationers are aware that the aesthetic appearance of the meals can increase or delay the appetite of those to whom the meals are served. Food is placed on the plate in a way to increase the appetite. Some people have limited food choices because they have a physical reaction. Responses vary among individuals and may include abdominal swelling, vomiting, itching and skin rash, wheezing, headache, and disturbed sleep.

Psychological Factors: Psychological factors are related to the mind and emotions. They differ from person to person, depending on their lifestyle and the person's upbringing. These are difficult to define. While the choices made as a result of emotions, self-confidence and attitudes may change day by day, some psychological factors such as beliefs, habits, values and past experiences with food have a permanent effect on the 
selected foods. Psychological factors may play a more dominant role in our food choices compared to other factors $(2,15,17)$.

Values: Value is a deeply personal sense of what is important. Values are strong enough to influence behavior and motivate action. A person's values can reflect the values of the family and culture in which they were brought up, or they can be a personal response to experiences encountered through life. During food selection, the values likely to influence the choices are related to food sources and health protection. For example, vegetarianism is a reflection of food choice.

Beliefs and Attitudes: People become owners of beliefs and attitudes by experiencing and learning. Beliefs and attitudes affect people's purchasing behavior. A belief is a defining thought of a person about something. Beliefs can be built on knowledge, conviction and creed. Feelings may or may not play a role in beliefs. Manufacturers are very concerned with consumers' beliefs about their products and services. Beliefs create product and brand images, and people act on the images of products and brands. When consumers are asked whether they like a product, advertisement or brand, they are actually asked to express their attitude (33). Attitudes are the outer defense of inner feelings and reflect people's tendency towards objects. Although beliefs and attitudes are similar to each other as the final outcomes of the learning process with their cognitive and motivational processes, there are important differences between them. These contain different attributes and consequences in terms of behavior. Therefore, it is very important to state both concepts differently in order to gain a solid scientific meaning. Beliefs about what is acceptable for food vary around the world and often depend on religion and cultural heritage. A belief is an opinion that need not be based on positive scientific evidence. Unlike durable values, beliefs can be challenged and changed. Many religions have food traditions and impose restrictions on what their followers eat. Besides religious traditions, some social groups and cultures have specific beliefs about food. Most of these beliefs cannot be confirmed. Some cultural beliefs often prohibit eating certain foods and lead to food taboos. These taboos are more common in primitive cultures.

Habits: Food choices are usually routine. A habit is a phenomenon that is done regularly without thinking. Their eating habits are the same and like all habits, it is not easy to change. Our food habits are sometimes unhealthy. Changing personal diet is not easy.

Ego: Ego refers to how we feel about ourselves and how we define our personal appearance, including the size, shape and weight of our body (body image). How we look physically (our strengths and weaknesses), how well coordinated we are, how shy or sociable we are, how well we manage our money, how we dress, how skilled we are to art, music, dance, how important we are in the family as brother, son or daughter. Selfesteem develops in childhood. Dissatisfaction with body image increases from the age of eleven to middle ages, especially for women. Also, the ego is not static and can change over time, even several times a day.

Motivation: A person has many needs at any given time. Some needs are biological. These needs arise from physiological states of tension such as hunger, thirst and restlessness. Other needs are psychogenic. In other words, it arises from psychological states such as being known, respecting one's person or belonging to a place. A need becomes a motive when it is brought to a sufficient level of compulsion and craving. This motif is a need that challenges one enough to take action.

Intuition: Intuition is when one selects, organizes, and interprets information data to create a meaningful picture of the world. Intuition depends not only on physical impulses, 
but also on the impulse's relationships with the surrounding field and on the conditions within the individual. The key word in the description of intuition is individual. People's intuition towards the same object is different.

Learning: Learning is a process in which individuals acquire knowledge and experiences regarding purchasing and consumption, guiding similar behaviors in the future. In other words, the consumption information and experiences obtained during the learning period guide the purchasing behavior. Experiences are used to meet the needs in determining attitudes and judgments about oneself or the environment, and this is the result of learning. Learning style is one of the most important factors affecting human behavior with its content and qualities. It benefits from learning and experiments in creating perceptions and concepts related to its own existence and environment in solving problems in meeting human needs. In general, people determine their needs and desires, especially their physical and instinctive needs through learning.

Perception: Perception is to learn about objects, events and relationships according to stimuli from the environment with the help of the sensory organs. However, perception is not only a physiological event, but also a subjective condition that is affected by the individual's beliefs, attitudes and personality traits. Individuals perceive them according to their opinions, beliefs and value judgments. The marketing components offered by the marketing manager and the component perceived by the target consumer may differ from each other. The target consumer's interpretation of new marketing components in a different way and in a way they want to see may cause some difficulties in the implementation of the marketing program. Perception is the physical and physiological aspects of the activity. Sensations are not independent events. A perception is made with almost every sensation. Thus, the simplest elements of psychological events are perceptions, not sensations. There is almost no sensation that does not end with perception. The effects from the environment stimulate the sensory organs, so as soon as the resulting nerve current reaches the brain, the sensory event occurs in a perception.

Attitude: Attitude refers to positive information and positive or negative emotions about a food. Attitudes can be learned through experiment and contact with other people. Attitudes often do not change often and remain unchanged. Attitudes sometimes have strong and sometimes weak effects. Consumers' attitudes towards a food or a firm affect the success or failure of the strategy. As a matter of fact, if the consumer has a negative effect on the marketing strategy of the business, he not only buys the food himself, but also affects the environment around him.

Personality: Each person has a different personality that affects their buying and selling. Personality is the distinct characteristics that cause a person to react consistently and constantly to his environment. Examination of strong correlations between certain personality types and food and brands, in which personality types can be classified, is an important variable in analyzing consumer behavior. Everyone has their own personality and inner structure. It is not always possible to decipher this personality. This can be possible with the determination of experiences and attitudes. Accordingly, the products to be consumed by each consumer and the brands to be preferred will be different. When marketers advertise consumer goods, they often emphasize features that everyone may find positive [33].

Social Factors: Together with the contact individuals have with each other (social factors), the cultures or societies people live in, affect their food choices. Your beliefs, traditions and taboos are influential factors. In addition, the effectiveness of the media, which is a part of daily life, in making certain food choices is not discussed. When 
choosing food, lifestyle, job and education, the size of the family and the importance and place of hospitality in the social group are also important $[2,4,7,11,18,19,20,30]$.

Culture, Subculture and Traditions: Culture determines the lifestyle of human beings as a member of each society. The consumption patterns, needs, priority order of needs and satisfaction of needs are a function of culture. Cultural values affect consumer behavior and consequently consumption. Cultural values are learned in the family, school and workplace through social interaction and strongly influence individual behavior. Culture is the most fundamental determinant of a person's desires and behavior. Each culture consists of smaller subcultures that describe the more specific identification and sociolysis of its members. Nationalities, religions, racial groups and geographical regions make up the subculture. Religious, racial, national, local and similar groups with common characteristics form subcultures. Traditions are phenomena that are repeated at specific times by members of a group or community. Special occasions include many traditional and special foods. Family traditions often revolve around food, as are important social and cultural traditions in most societies.

Lifestyle: People of the same social class, subculture, and even the same profession can have very different lifestyles. The life system of a person is the lifestyle that is expressed in his activities, interests and ideas. Lifestyle can involve more than a person's social class and personality. If a person's social class is known, some speculation or interpretation can be made about his possible behavior, but this may not give him a full view. Lifestyles can also affect purchasing behavior [9]. In general, lifestyle factors that influence food choice are as follows.

Occupation: The occupation of the consumer primarily determines his income. In addition, working time, time spent commuting to work, leisure time, and evaluation style are important for an individual's food consumption. What you choose to eat may depend on the physical demands of your business. Active jobs require the worker to eat more carbohydrates to increase energy, while those who require less physical activity should be careful not to overeat.

Education: Smart options arise from knowing more about options. All kinds of communication help us know better about our food, which determines our choices. A person's better knowledge of the nutritional content, nutritional requirements, and food preparation of foods increases the likelihood of smart food choices.

Geographical location (Ecology): A country's basic foodstuffs depend on the ability to grow according to geography and climatic conditions. If the climate is tropical, foods such as sugar cane, pineapple, banana and coconut, if Mediterranean herbal and for the rural inland high-cold regions predominantly meat. Climate affects not only the types of food grown in a region, but also food choices. Summer brings the desire for fresh fruits and vegetables, ice cream and light meals, while winter is the season for soups, hot drinks and hot desserts.

Social Interaction: The result of globalization is that everyone goes everywhere, the internet allows us to shop from remote locations and trade deals between countries mean that an event in the far corner of the world can be felt in the rest of the world. While traveling, we meet a wide variety of dishes that we enjoy and will start looking for on the way back. Personal and close friends' interests affect their food preferences.

Family, Household Structures and Roles: The influence of family members on the recipients is very strong. The family is the most important consumer purchasing 
organization. Marketing managers are closely concerned with the influence and roles of spouses and children in purchasing various products and services. These roles can be divided into five groups: opinion makers, influencers, decision makers, actual buyers, and users. Sometimes all or a few of these roles can be combined with one person. It serves family members, a subculture that transmits the cultural values of the society. The child acquires his social and cultural values and consumption habits from the family and carries their traces throughout his life. Therefore, it is possible to explain consumption habits with the life curve of the family. The structure of the family union determines the type, quality and amount of food consumed at a meal. For example, young children with very delicate taste buds may prefer less spicy foods, while seniors may show a slight sense of taste and prefer more flavored (especially salty and sweet) foods. Personal favorites within the household are often the most important factor in food selection. More attention needs to be paid to the preparation of food in an attractive and enjoyable way to meet the family's different dietary needs.

Roles and Status: The position of individuals in each of the groups such as family, club and association can be considered in terms of role and status. Each of the roles affects purchasing behavior. Each role has a specific status in society. Products can serve as status symbols for social classes, depending on geographical situation and even time. The personal characteristics of a person affect his purchasing decision. Among these features are his age, life period, profession, economic situation, lifestyle and personality and what he thinks of himself.

Social Class and Social Interaction: One of the sociocultural factors affecting the perceptions and purchasing behaviors of the consumer is the social class in which consumers are located. The concept of social class is a complex concept. Classifications of society are made from various angles, and different roles and rewards are prescribed to classes. Changes between roles and awards are determined. For example, society is divided into classes according to the criteria of managers, income and the type of work done. The classification in question is the vertical grouping of society in the form of lower, middle, and upper classes. In reality there is no clear boundary between these classes. In addition, the people who make up the classes cannot either change their place within the class or those in the lower class make an effort to move to the upper class. The food has long been a symbol of friendship and hospitality. When your guests come to your house, one of the first things you do is offer them something to eat and drink. Meals help even a shy person to create a comfortable environment where they can be a part of the group by keeping themselves busy by preparing or serving meals.

Reference Groups: Reference groups are people or groups that serve as the point of comparing values in the formation of attitudes and behaviors. The concept of reference is not limited to group size and membership and does not include a condition for identification with a group. In other words, the group can be symbolic, such as famous businesspeople, pop music stars or sports heroes. Reference groups used especially for attitudes and behaviors are called comparative reference groups. These groups may be neighbors whose lifestyle, home layout, furniture and automobile choices are admirable and valued in imitation. The same phenomenon applies to food.

Media: Media plays a big role in the food choices we make. Advertising of food is everywhere; every day we live in the noise from thousands of advertisements, magazines, billboards, radio, cinema, internet and television. Most of the foods advertised in the media are lower in nutritional value than their unprocessed or less refined alternatives. However, these products are presented as the foundation of a healthy and happy lifestyle. 
Friendship and Peer Groups: One of the biggest factors in the purchasing behavior of the person and the purchasing process is the circle of friends. The circle of friends is an important factor in differentiating the attitudes in the selection of products and services in the search for information. An individual's peers are roughly the same age group of people of the same social status. Peer group influence is strongest in adolescence. In need of acceptance, teenagers eat what their friends eat, rather than those which their parents would think they should eat and what is nutritiously good. Trying new things in a peer group is safer and sharing food is a good way to get to know people and develop friendships.

Hospitality at home: The family having fun in the home environment is more informal. Cooking for others at home is an important social activity in daily life for ready consumption within the frame of the intensity of consumers' lives. Working parents don't have time to shop and cook for dinner parties. It is easier to use takeaway meals or to go to a restaurant where others prepare tables.

Economic Factors: Food selection is what products people buy and eat, and how they decide on this. Staying within certain budget limits affects our choices [2, 21].

Economic Conditions: As examined in the demographic dimensions of global consumer markets, the economic situation of the person is one of the main factors affecting the product and brand selection [33]. The economic situation depends on the level of disposable income, its stability, the time of taking over, savings and liquidity, asset values, credit and preferences between spending and saving. Producers and sellers of foods that are particularly sensitive to income follow these indicators closely. For example, if there is a recession, they redefine food and reduce locations, prices, production, and stocks. Economic factors affecting the consumer market are analyzed from two sides. First, to determine the purchasing power of the entire population, the national economy and trends in the economy and then the data on individuals and families are analyzed. The general economic situation and changes in the economy affect the purchasing and consumption tendency of the consumers. The imbalance of supply and demand, inflation and interest rates are economic factors that affect consumer decisions. Fluctuations in these factors should be recognized, the reasons should be determined, and the relevant economic and monetary policy of the state should be reviewed.

Cost of Food: Cost is one of the most important factors when choosing food. It is especially important for low-income families, students and the elderly. The proportion of these groups' spending on food is important in their total income. The costs of food vary with various factors; how much can be bought at a time (storage space is available, a more economical purchase can be made with large quantities), whether the food is seasonal or local, how much the food is processed (marinated meat products or instant salads, in many cases poorly processed foods, for example, freshly squeezed juices and fruit salads are sold more expensive than the regular product). If the place of purchase is carefully chosen, it can save money on a market or roadside purchase, however there are usually no guarantees of reimbursement, purchase of store specials and generic brands (which large supermarkets produce with their own labels) [33].

Available resources: Time is a limited resource for the purchase and preparation of ingredients required for food, which is wasted unless cooking skills are used. Resources can be used interchangeably. If you have money, you can choose to dine outside, but if you are economically not able to eat outside, you can use your skills, knowledge, and food ingredients to make a meal. Time and money can be used wisely by safely storing larger quantities of food than what is on sale or immediately available in season. 
Market place: Market refers to the place where consumers buy food. Generally, the smaller the outlet, the more expensive the food items. Small stores buy food products from larger stores or wholesalers and increase the selling price to cover their expenses.

Profession and Financial Power: A person's choice of work affects the choice of food. The physical demands and social expectations of the job are reflected in food choices. Income from employment also determines the quality and quantity of selected foods. For everyone, economic factors are paramount when purchasing food.

\section{NEW TRENDS IN CONSUMERS' FOOD BEHAVIOR}

In recent years, significant changes have been observed in the food behavior of consumers. Economic, demographic, cultural, social, or environmental determinants affect the formation of new phenomena such as globalization, provisioning, virtualization, ecologization and rationalization (Figure 1) [10,21].

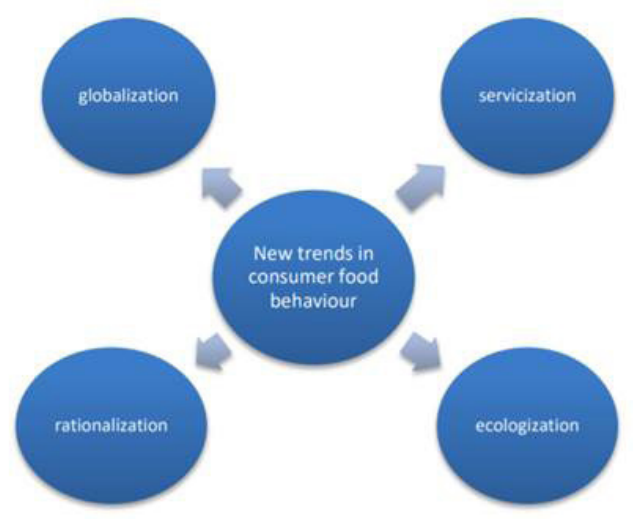

Figure 1. New trends in consumers' food behavior

The globalization of consumption is manifested by the penetration of food consumption patterns across cultures. Among the various factors that contribute to the assimilation of food consumption patterns, the following points should be noted:

1. Increase of international and local retail chains (hyper and supermarkets and discount stores),

2. Development of internet and social media,

3. Development of fast-food chains,

4. Spread of prepared foods,

5. Facilitated mobility,

6. Nutritional recommendations for rational nutrition,

7. Mediterranean diet (higher intake of vegetables and fruits, lean meat, vegetable oils),

8. Loss of specific national features typical for each country. 
It should be noted that, due to the dominance of the American consumption model, the globalization of the consumption process is often defined by Americanization or McDonaldization. This means combining the needs of specific goods and services globally. It should be noted that the unification, in response to the traditions and general culture of consumers, is seeking to express their national identity with an ethnocentric approach to more and more consumers. In this case, consumers do not buy a foreign product if they think that they may harm the economy and employment in the country of origin. Therefore, traditionally produced regional products are increasing in popularity, and companies that offer such goods are more and more respected.

The fact of putting consumption into service is associated with a decrease in consumption in the material sphere due to its growth in the intangible sphere. This leads to more purchases of intangible goods, like services. This trend also applies to food consumption. Eating out is increasingly practiced around the world, although it significantly affects the structure of household spending. There is a steady increase in the number of people eating out. Also, attention should be paid to a certain transformation of consumers' approach to products. At present, they want to opt for a variety of experiences rather than tangible assets. Therefore, the phenomenon known as the "Sensory Market", where products offer consumers a stronger and more intense opportunity to experience, experiment and take risks, is growing in popularity.

New trends in consumers' food behavior may be the virtualization of online shopping as well as the behavior associated with the growing popularity of grocery stores. E-commerce is becoming increasingly popular among companies, with consumers seeking alternative ways to purchase goods and access information about them, as well as those seeking access to new markets. According to many studies on the factors that cause satisfaction of consumers from online shopping, four main factors that affect the consumers' perception of Internet content can be distinguished:

1. Security and privacy when shopping online,

2. Website design,

3. Website reliability,

4. Website customer services.

Grocery online shopping is becoming more and more popular among consumers. There are currently a large number of online supermarkets where consumers can find almost all the food products they need and even deliver free of charge in the way they are most comfortable. It should be noted that many consumers still buy things (especially food) in traditional stores, but many of them link these two forms of shopping and there are a growing number of consumers buying only from online retailers.

While discussing the trends in consumption of food products and the nutritional behavior of consumers, very important facts in terms of environmentally friendly and rationalized food consumption should not be ignored. More and more consumers are opting for healthy, safe, traditionally produced products that reduce waste. In addition, they want to use renewed resources. Consumers believe that changing their diet and using supplements are two of the most important conditions for reducing treatment costs and improving overall health. In addition, numerous educational campaigns promoting healthy and rational lifestyles contribute to the critique of consumerism and try to persuade consumers to rationalize many areas of consumption, including nutrition. These conditions, which are 
compatible with the concept of sustainable consumption, have influenced the development of the Voluntary Simplicity (VS) movement, which is an externally simple and self-rich lifestyle. This trend, related to food or diet, is purchasing sustainable products, extending the life cycle of products, avoiding waste, recycling, and transportation. Table 1 presents some examples of new trends in consumer activity as assessed by consumer food behavior and specific trends $[10,16,17,18]$.

\section{MARKETING STRATEGIES OF FOOD MANUFACTURERS}

Marketing strategies suggest that it should include ways to minimize pre-decision risk in order to reduce the concern on making a frequent or important purchase. The most common marketing tools defined as controllable parameters used to influence the consumer purchasing process are the "marketing mix", which includes product, price, place, and promotion (conventional framework). It differs from other classifications such as a good and service mix, distribution mix, or communication mix.

Table 1. Some examples of new trends in consumer activity are associated with consumer food behavior and particular trends.

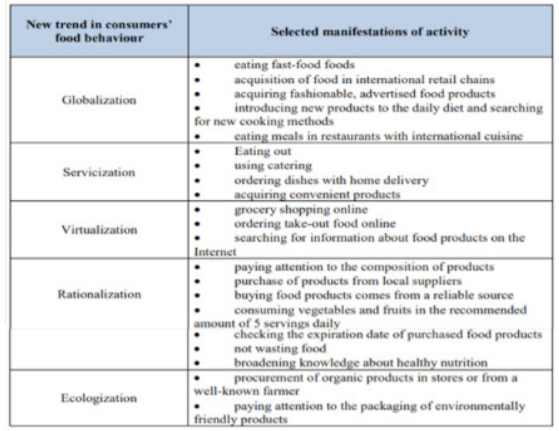

It has been found that the 4P mix is adapted for a variety of fields, including retail marketing. The store environment of the 4Ps mix is expanded with the inclusion of new elements such as store formats, personnel, and physical evidence. In the context of food retailing, it is stated that traditional marketing mix elements such as product quality and packaging, store location, price and promotional tools shape the purchasing behavior of consumers. Moreover, consumers tend to perceive environmental factors such as the atmosphere and personnel more when shopping in the supermarket. It should be noted that these factors affect the perceived value of consumers and their purchasing decisions for food products. If a company is to be profitable, it must create value for the product that meets the expectations of the consumer, while also generating profit for the producer. Researching current consumers' preferences, creating profiles, adapting actions to new trends and exchanging value with consumers is a prerequisite for an effective marketing strategy. The company's activities to create an effective marketing, include selecting the target market, determining the desired positioning of the products in the consciousness of the target consumers and determining a marketing action plan to achieve the desired positioning. In food companies, marketing decisions are usually the initiatives that bring the company's marketing efforts strategically to the highest return, based on some market and company analysis such as Porter's five forces Analysis of 5C, Marketing Mix Analysis, Pest Analysis, Breakeven Analysis. 
The development of a marketing strategy starts with the consumer. However, determining target markets is a prerequisite. First, the company must segment its food market consumers and find the best way to characterize and differentiate them. Demographic (age, gender, income), geographic (country of origin, urban or rural) and lifestyle (hedonistic or valuebased) criteria should be considered.

When formulating a marketing strategy, it is also necessary to take into account the appropriate selection of staff, training tailored to the specific nature of a commercial offer and the motivation, evaluation and control system to ensure the appropriate one. It should be noted that grocery stores are often a place of discovery and purchase. So, some consumers who buy a particular brand or product for a long time are tired and decide to change something. Therefore, a very important element of the company's strategy is to pay attention to the continuous product range development. The basis of an effective marketing strategy is to learn about and analyze customer needs and to consider the results of a new product during the design phase. As long as the company understands and shapes customer acquisition and retention, it is called "producer-consumer relationship management". A well-designed customer management system strengthens customer loyalty, which leads to higher profits [33].

\section{EVALUATION AND CONCLUSION}

The success of food companies today consists of two combined conditions; It is a combination of the efficiency of the functioning of the organization and the foreign and non-market conditions. Market orientation becomes a must in a competitive and sustainable buyer market and the company's success depends on the quality of meeting consumers' needs. Marketing has an important role in forming the strategies of companies, because in this way, the value of the consumers is created by meeting the needs of the consumers. A well-functioning marketing unit has an important role in the structure of every institution. The role of marketing is to be open to the needs and changing needs and preferences of the consumer.

The new trends in food behavior described above have a significant impact on the marketing strategy of companies in the food industry, in their suggestions and distribution in a way that meets the expectations of the buyers as much as possible. The technological advancement, globalization, provisioning and virtualization of consumption contribute to the situation where people seek products and services that can meet their needs. Consumers look for food alternatives that will allow them to shorten food preparation time, use their leisure time for work or rest, avoid wasting time for cleaning, maintain a balance between work and leisure life and maintain good health. In contrast, food companies offer new innovative products and services that will delight consumers, such as market-friendly and functional food products and specialized catering services. More and more restaurants attract customers with unique and attractive localization, arrangements or menu suggestions designed to stimulate their imagination and provide unusual impressions and emotions. Responding to new trends in consumer service and globalization, manufacturers should have the following characteristics [22, 23, 33];

1. Food production tailored to the individual nutritional needs of consumers or consumer groups,

2. Gastronomy development in modern shopping and entertainment centers,

3. Development of regional brands, confirmed by a certificate that guarantees the high quality of products, their origin in a particular region and the use of traditional production methods, 


\section{Setting up online platforms and supermarkets to purchase food products and meals online or by} phone,

\section{Using recyclable, biodegradable food packaging.}

Changing consumer trends and manufacturers' reactions to food behavior play a key role in the success of product services (Table 2). Today's consumers are aware of foodborne illnesses or dangers and pay more attention to environmental protection. For this reason, they are watching products whose ingredients are preserved or must contain no or minimal content and amount of controversial ingredients. The ecological concept is very popular with consumers. Ecologization of consumption is one of the most characteristic contemporary trends in consumption processes. This phenomenon has a significant impact on the management processes in organizations. Consumers pay more attention to the producers' attitude towards the natural environment. Greening consumer behavior is an important reality, as companies are involved in proposals that will be competitive not only in terms of price but also in terms of benefit and quality based on safety for health and the natural environment $[10,16,18]$.

Table 2. Producers' reactions to new trends in consumers' food behavior

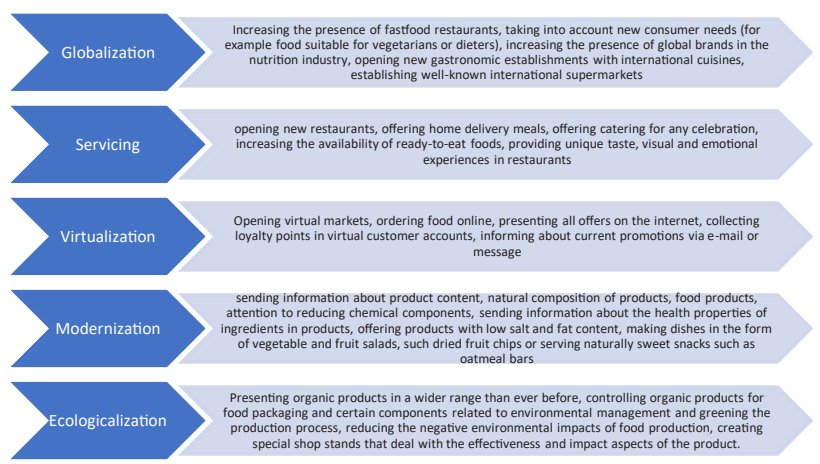

The demand for raw materials and energy-efficient products that generate less waste, as well as products that are safe for human health (e.g. organic food) is still increasing. As many scientists point out, there is a growing need for safe and healthy foods with higher quality characteristics. In addition, traditional products with regional character have a positive relationship with consumers and are increasingly preferred. More important, consumers are willing to pay higher prices for such products $[8,14]$.

In addition, consumers are increasingly reacting to the eco-innovation proposed by businesses. This offers companies new growth opportunities. Among the initiatives that can be observed in the strategies of companies based on the trend of ecology and regionalization of food consumption are ISO (International Organization for Standardization) and EMAS standards (EU Eco-Management and Audit Scheme). Also, a new approach to the production of products taking into account all life cycles (controlling and greening the production process, using and disposing of the product), ecological product innovations (researching new technological solutions that reduce negative environmental impact) and development is the distribution of pro-ecological products. Attention should also be paid to the use of environmental issues in marketing and advertising. In addition to using the ecological trademarks system, it is important to use generally understood environmental protection issues in advertising messages. 
Some studies show that the supplier green innovation path provides significant benefits to the company's environmental performance and competitive advantage $[8,33]$.

In the market economy, the consumer is the focus of attention. The success of a company that produces and sells products depends on the market decisions of consumers. Information about consumer behavior and the factors that shape the consumer is the basis of the company's marketing strategy. The aim of this study was to identify and discuss the most important trends in the nutritional behavior of consumers that contribute to the development of marketing strategies for food companies. In the studies covered in this article, it is observed that some examples of new trends in the food behavior of consumers are globalization, service, virtualization, ecology and rationalization of consumption. This phenomenon has a significant impact on the marketing strategy of companies trying to make suggestions and distributions from the food industry in a way that meets the expectations of consumers as much as possible. Some activities related to new trends in food consumers' behavior include the creation of new innovative food products (e.g. convenience or functional food products) and services (e.g. attractive restaurants, online platforms and supermarkets for purchasing), development of regional brands based on health and natural environmental safety. The development of the production of proecological products suitable for quality can be distinguished. Future research may focus on issues related to marketing communication methods that are most effective for the food industry.

\section{REFERENCES}

[1] Anon., "Factors affecting food choice", www.meatandeducation.com, 12s., 2012.

[2] Anon., "Influencing Consumer Behaviour: Improving Regulatory Design", Australian Government, Department of Finance and Deregulation, Office of Best Practice Regulation, 73s., 2013.

[3] Anon., "Factors Affecting Food Selection", http://factorsaffectingfoodselection.weebly.com/index.html, 2017a

[4] Anon., "Factors Affecting Food Choices Culture Social Emotions Agriculture, Technology, Economics, Politics", 24 s.

https://mrssgordon.wikispaces.com/file/view/Factors+Affecting+Food+Choices.pdf, $2017 b$.

[5] Anon., "Influences on Food Choices and Food Patterns", MHR Unit 1, 22s., https://www.mheducation.ca/web_resources/sch/mhr_ffl_sample_ch01.pdf, 2017c.

[6] A. Annunziata, R. Vecchio, "Factors affecting use and understanding of nutrition information on food labels: evidences from consumers", Agriculture Economics Review, 13(2), 103-116, 2012.

[7] S. Bleich, "Impact of environmental factors on individual food choices", World Health Summit October 21, 19 s., 2012.

[8] B. J. Bronnenberg, J. H. Dubé, "The Formation of Consumer Brand Preferences", Working Paper 22691, National Bureau of Economic Research, NBER Working Paper Series, 49 s., 2016. 
[9] H. H. Chovanová, A. I. Korshunov, D. Babčanová, "Impact of Brand on Consumer Behavior", Procedia Economics and Finance 34 (2015), 615 - 621, 2015.

[10] G. Hanus, “The influence of the trends in consumers' food behavior contributing to the formulation of marketing strategies for food companies", World Scientific News, (112), s. 85-95, 2018.

[11] S. Higgs, J. Thomas, "Social influences on eating", Current Opinion in Behavioral Sciences, 9(June), s. 1-6, 2016.

[12] C. Hunter, "Nutrition Matters: Trends Affecting Food Choices", Nutrition File for Health Educators, 9s. 2010.

[13] Lau, D., Krondl, M., Coleman, P. "Psychological Factors Affecting Food Selection", J. R. Galler (ed.), Nutrition and Behavior (C) Plenum Press, New York, 1984.

[14] A. Kara, J. R. Méndez, O. Küçükemiroğlu, T. Harcar, "Consumer preferences of store brands: Role of prior experiences and value consciousness", Journal of Targeting, Measurement and Analysis for Marketing, (17), s. 127 - 137, 2009.

[15] I. H. Kaya, "Motivation Factors of Consumers' Food Choice”, Food and Nutrition Sciences, (7), s. 149-154, 2016.

[16] V. Kumar, N. Umashankar, Y. Bhagwat, "Assessing the Influence of Economic and Customer Experience Factors on Service Purchase Behaviors", Marketing Science, 33(5), 673-692, 2016.

[17] T. Lautiainen, "Factors affecting consumers' buying decision in the selection of a coffee brand", Saimaa University of Applied Sciences Faculty of Business Administration, Lappeenranta Degree Programme in International Business, 40 s., 2015.

[18] B. Melovic, D. Cirovic, B. Dudic, T. B. Vulic, M. Gregus, "The Analysis of Marketing Factors Influencing Consumers' Preferences and Acceptance of Organic Food Products - Recommendations for the Optimization of the Offer in a Developing Market", MDPI, Foods (9), 25, 2020.

[19] M. Murimi, M. Chrisman, H. R. McCollum, O. Mcdonald, “A Qualitative Study on Factors that Influence Students' Food Choices”, Journal Nutri Health, 2(1), 2016.

[20] M. Nestle, R. Wing, L. Birch, L. DiSogra, A. Drewnowski, A., S. Middleton, S. Sigman-Grant, W. Jeffery Sobal, M. Winston, "Behavioral and Social Influences on Food Choice", Nutrition Reviews, 56(5), s. 50-74, 1998.

[21] T. H. Nguyen, A. Gizaw, "Factors that influence consumer purchasing decisions of Private Label Food Products", A case study of ICA Basic, School of Business, Society and Engineering, Bachelor thesis in Business Administration FOA214, 92 s., 2014.

[22] P. Nowicki, T. Sikora, "Consumer Behavior at the Food Market", Research Gate, 9s., 2012.

[23] I. Popovic, B. A. K. Bossink, P. J. Sijde, "Factors Influencing Consumers' Decision to Purchase Food in Environmentally Friendly Packaging: What Do We Know and Where Do We Go from Here?", Sustainability, (11), 22, 2019.

[24] V. Ree1, N. Riediger, M. H. Moghadasian, "Factors affecting food selection in Canadian population", European Journal of Clinical Nutrition 62, 1255-1262; published online 1 August 2007, 2008. 
[25] M. A. Razali, N. Zainol, K. H. Rezo, F. N. Tazijan, M. A. Ahmad, S. Rahim, N. Nordin, "Psychological Factors Affecting Universities' Students Food Choice", ETAR2014, Volume 1, s. 384-390, 2014.

[26] K. Roininen, "Evaluation of Food Choice Behavior: Development and Validation of Health and Taste Attitude Scales, University of Helsinki Department of Food Technology, To be presented, with the permission of the Faculty of Agriculture and Forestry of the University of Helsinki, for public criticism in lecture hall B2, Viikki on May 11th, 55 S., 2001.

[27] Y. B. Saygı, “Gıda Seçimini Etkileyen Faktörler” I, Dünya Gıda Dergisi, 2017.11, s. 76-81, 2017a.

[28] Saygı, Y. B. (2017b). Gıda Seçimini Etkileyen Faktörler II, Dünya Gıda Dergisi, 2017.12, s. 78-83, 2017 b.

[29] R. Shepherd, "Influences on Food Choice and Dietary Behavior", University of Surrey, UK, 68 s., 2017.

[30] S. Souter, C. S. Keller, "Food Choice in the Rural Dwelling Older Adult", www. snrs.org, 5(3), 19, 2002.

[31] D. Thiruselvakumar, K. Sinuvasan, R. S. Chakravarthy, E. Venkatesh, "Factors affecting food choice and attitude of choosing food items among adolescents in South India”, International Journal of Scientific and Research Publications, 4(4):3, 2014.

[32] J. Vesela, S. Grebenova, "The Influence of Psychological and Social Aspects on the Eating Habits of Primary School Children", School and Health 21, Health Education: Contexts and Inspiration, s. 271-284, 2010.

[33] R. Vyas, J. K. Sharma, R. B. Sharma, "A Study on Consumer Behavior Towards Select Branded Food Items, IOSR Journal of Business and Management (IOSR-JBM), 18(8), s. 01-08, 2016.

[34] E. B. Zielinska, "Role of Psychological Factors in Food Choice-A Review", Polish Journal of Food and Nutrition Sciences, 15/56(4), s. 379-384, 2006. 